\title{
KEPUASAN KERJA GURU DITINJAU DARI PERAN SUPERVISI KEPALA SEKOLAH DASAR NEGERI DI KECAMATAN BOGOR UTARA
}

\author{
Yudhie Suchyadi $^{\left.a^{*}\right)}$, Nita Karmila ${ }^{a}$, Nurlinda Safitri ${ }^{a)}$ \\ a) Universitas Pakuan, Bogor, Indonesia \\ ${ }^{*}$ e-mail korespondensi : ydhie.schyadi@gmail.com
}

Riwayat Artikel : diterima: 21 Juli 2019; direvisi: 27 Juli 2019; disetujui: 26 Agustus 2019

\begin{abstract}
Abstrak. Secara umum penelitian ini bertujuan untuk meneliti kepuasan kerja guru dan variabel-variabel yang memiliki hubungan dengan kepuasan kerja guru, dalam hal ini adalah supervisi kepala sekolah serta upaya untuk meningkatkan kepuasan kerja guru. Metode yang digunakan dalam penelitian ini adalah metode survei dengan pendekatan korelasional. Variabel penelitian terdiri dari variabel bebas yaitu supervisi kepala sekolah dengan variabel terikat yaitu kepuasan kerja guru. Penelitian ini dilakukan di SD Negeri yang berada di kecamatan Bogor Utara Kota Bogor. Pengumpulan data penelitian dilakukan dengan menyebarkan kuesioner terhadap responden yang telah terpilih sebagai sampel. Hasil kuesioner dikumpulkan dan dicatat dalam rangka menganalisa data untuk menguji hipotesis penelitian dan untuk mengetahui kekuatan hubungan antara supervisi kepala sekolah dengan kepuasan kerja guru. Untuk menguji hipotesis penelitian dan untuk mengetahui kekuatan hubungan antara supervisi kepala sekolah dengan kepuasan kerja guru dilakukan analisa data menggunakan uji statistik berupa korelasi dan regresi linier sederhana, serta korelasi dan regresi ganda. Pengujian hipotesis dilakukan pada taraf signifikasi $\alpha=0.05$. Penelitian ini menghadirkan tiga kesimpulan utama yaitu Terdapat hubungan positif antara supervisi kepala sekolah dengan kepuasan kerja guru, artinya semakin tinggi supervisi kepala sekolah maka semakin tinggi kepuasan kerja guru yang ditunjukan dengan persamaan regresi $\hat{Y}=63,64+0,53 X$ dan koefisien korelasi ry $=0,520$. Berdasarkan hasil temuan, maka kepuasan kerja guru dapat ditingkatkan melalui supervisi kepala sekolah.
\end{abstract}

Kata Kunci: supervisi kepala sekolah, kepuasan kerja guru

\section{WORK SATISFACTION TEACHERS ARE REVIEWED FROM THE ROLE OF HEADMASTER SUPERVISION OF PRIMARY SCHOOL IN NORTH BOGOR DISTRICT}

Abstract. This research is aims to examine teacher job satisfaction and variables that have a relationship with teacher job satisfaction, in this case the supervision of school principals and efforts to improve teacher job satisfaction. The method used in this study is a survey method with a correlational approach. The research variable consisted of an independent variable namely the supervision of the principal with the dependent variable namely teacher job satisfaction. This research was conducted at the Public Elementary School in North Bogor Regency, Bogor City. Research data collection is carried out by distributing questionnaires to respondents who have been selected as samples. The results of the questionnaire were collected and recorded to analyze data to test the research hypotheses and to find out the strength of the relationship between principal supervision and teacher job satisfaction. To test the research hypothesis and to determine the strength of the relationship between principal supervision and teacher job satisfaction, data analysis was performed using statistical tests in the form of correlations and simple linear regression, as well as multiple correlation and regression. Hypothesis testing is performed at the significance level $\alpha=0.05$. This study presents three main conclusions: There is a positive relationship between principal supervision and teacher job satisfaction, meaning that the higher the supervision of the principal, the higher the teacher job satisfaction shown by the regression equation $\hat{Y}=63.64+0.53 \mathrm{X}$ and the correlation coefficient $\mathrm{r}_{\mathrm{y}}=0.520$. Based on the findings, teacher job satisfaction can be increased through supervision of the school principal.

Keywords: school principal supervision, teacher job satisfaction.

\section{PENDAHULUAN}

Pendidikan adalah faktor yang paling penting dan prioritas utama yang membutuh-kan perhatian serius dari semua pihak, karena pendidikan adalah penentu kemajuan bangsa di masa depan [1]. Tujuan dan cita-cita nasional, untuk kehidupan intelektual bangsa terkandung dalam UUD 1945. Pemerintah bersama masyarakat terus mencari pengembangan pendidikan demi terwujudnya bangsa yang mandiri, unggul dan siap menghadapi dunia globalisasi [2]. Meningkatkan kepuasan kerja bagi guru merupakan hal yang sangat penting, karena menyangkut masalah hasil kerja guru yang merupakan salah satu langkah dalam meningkatkan mutu pelayanan kepada siswa. Aspek yang berkaitan dengan guru adalah menyangkut citra/mutu guru dan kesejahteraan.
Salah satu hal yang patut dipertimbangkan bagaimana upaya untuk meningkatkan kualitas guru adalah dengan cara meningkatkan kepuasan kerjanya, sebab dengan kepuasan kerja guru yang meningkat maka guru akan berusaha untuk meningkatkan profesi dan mutunya dengan demikian diharapkan keberhasilan pendidikan akan tercapai.

Kepuasan kerja guru itu bisa ditingkatkan dengan beberapa cara diantaranya adalah organisasi dapat membuat iklim organisasi yang berpihak pada kesejahteraan guru, terbuka dan menekankan pada prestasi, bisa pula kepuasan ditingkatkan menggunakan faktor iklim organisasi yang diantaranya pengaruh supervisi kepala sekolah dan kecerdasan emosional [1].

Pencapaian tingkat kepuasan kerja guru tidak terlepas dari kepemimpinan kepala sekolah, salah satu tugas 
pemimpin adalah melakukan supervisi. Dengan melakukan supervisi seorang kepala sekolah berarti telah memberikan bantuan dan layanan untuk meningkatkan kualitas belajar mengajar guru di kelas untuk meningkatkan kualitas belajar siswa [2].

Proses supervisi merupakan salah satu aspek yang cukup dominan dalam menilai efektifitas manajemen yang ada di sekolah. Eksistensinya diperlukan tidak hanya untuk membina, membimbing dan membantu guru dalam rangka memperbaiki dan meningkatkan kinerja dalam pengelolaan pembelajaran, tetapi juga sebagai perekat antarwarga sekolah sehinngga dapat saling bekerja sama secara sinergis dalam mewujudkan tercapainya tujuan sekolah [1].

Kepuasan kerja dipengaruhi oleh banyak faktor dan salah satu diantaranya adalah supervisi kepala sekolah [1]. Hal ini didasarkan pada asumsi bahwa para guru bekerja selain untuk mengharapkan imbalan baik material maupun non material namun mereka juga menginginkan iklim yang sesuai dengan harapan mereka seperti terdapat keterbukaan dalam organisasi, kondisi kerja, terdapat perhatian, dukungan, penghargaan, kesempatan promosi, pendapatan yang layak dan rasa adil dari kepala sekolah karena tidak semua pimpinan memberikan penghargaan terhadap guru yang sudah berprestasi atau menunjukkan kinerja baik, dan kurang mendapat kesempatan untuk mengembangkan diri. Hal tersebut dapat mengakibatkan guru berprilaku datang terlambat, kadang-kadang tidak masuk sekolah, kurang bertanggung jawab, tidak punya semangat dan motivasi bekerja. Bila dibiarkan maka akan berdampak pada perilaku kerja guru dalam mendidik para siswa di sekolah yang pada akhirnya akan bermuara pada penurunan kualitas pendidikan secara keseluruhan.

Berdasarkaan pada pemikiran di atas, maka dalam penelitian ini dirasa perlu untuk mempelajari atau mencermati kepuasan kerja guru yang dihubungkan dengan variabel-variabel lain. Penelitian dilakukan di Kecamatan Bogor Utara dan yang menjadi responden dalam penelitian adalah guru-guru SD Negeri. Variabel yang diteliti dibatasi variabel bebas yaitu supervisi kepala sekolah serta variabel terikatnya adalah kepuasan kerja guru.

Menurut J. Wood, J. Wallace, dan R.M. Zeffane [3], yang didukung pendapat dari Stephen P. Robbins, kepuasan kerja adalah sejauh mana individu merasa positif atau negatif tentang pekerjaannya. Indikator yang dikemukakannya adalah: a) pekerjaan, yaitu tanggung jawab, minat, dan perkembangan; b) hubungan dengan rekan kerja, yaitu hubungan yang harmonis dan saling menghormati; d) peluang promosi, yaitu kesempatan untuk kemajuan lebih jauh; dan e) bayaran, yaitu bayaran yang di sarankan cukup dan adil dibandingkan dengan bayaran lain yang diterima.

Seiring dengan pendapat sebelumnya, menurut Fred Luthan [4], kepuasan kerja adalah hasil dari persepsi karyawan mengenai seberapa baik pekerjaannya memberikan hal yang dinilai penting. Indikator yang dinyatakan, yaitu: a) pekerjaan itu sendiri yaitu pekerjaan yang memberikan tugas yang menarik, kesempatan untuk belajar, dan kesempatan untuk menerima tanggung jawab, b) gaji, yakni sejumlah upah yang diterima dan tingkat di mana hal ini dipandang sebagai hal yang dianggap pantas dibandingkan dengan orang lain dalam organisasi, c) peluang promosi, dimana kesempatan diberikan untuk maju dalam organisasi, d) pengawasan, adanya kemampuan penyelia untuk memberikan bantuan teknis dan dukungan perilaku, e) rekan kerja yaitu sejauh mana rekan kerja pandai secara teknis dan medukung secara sosial.

Menurut Kreitner dan Kinicki [5], terdapat lima faktor yang dapat mempengaruhi timbulnya kepuasan kerja yaitu :

a. Pemenuhan kebutuhan (Need Fulfillment),

b. Kesenjangan (Discrepancies),

c. Pencapaian nilai (Value Attainment),

d. Keadilan (Equity),

e. Komponen genetik (Dispositional/ Genetic Components),

T. Hani Handoko [6] mengemukakan bahwa kepuasaan kerja (job satisfaction) adalah keadaan emosional yang menyenang atau tidak menyenangkan dengan mana para karyawan memandang pekerjaanya. Hal ini nampak dalam sikap positif karyawan terhadap pekerjaan dan segala sesuatu yang dihadapi di lingkungan kerjanya, karena hal itu mempengaruhi tingkat absensi, perputaran tenaga kerja, semangat kerja, keluhan-keluhan, dan masala-masalah personalia lainnya. .

Berdasarkan uraian teori di atas, dapat disimpulkan bahwa kepuasan kerja adalah sikap dan perasaan guru terhadap pekerjaannya terkait dengan situasi kerja, imbalan /gaji, hubungan dengan atasan, kerjasama antar personal dan hal-hal lain yang menyangkut fisik dan psikologis a. Adapun indikator-indikatornya: a) sistem penggajian, b) reward / apresiasi pimpinan dan kesempatan untuk promosi, c) perlakuan adil dari pimpinan (pengakuan) d) sarana yang kurang memadai,e) lingkungan kerja hubungan dengan rekan kerja serta sarana yang menunjang pekerjaan.

Syaiful Sagala [7] menyatakan bahwa supervisi kepala sekolah merupakan serangkaian usaha untuk memperbaiki situasi belajar mengajar seperti bantuan bagi guru-guru dalam melaksanakan pengajaran, untuk membantu siswa agar lebih baik dalam belajar. Namun kenyataannya di mata masyarakat masih banyak orang beranggapan bahwa supervisi kepala sekolah identik dengan pengawasan yang berbau inpeksi. Padahal secara umum supervisi berarti upaya bantuan kepada guru agar guru dapat membantu para siswa belajar untuk menjadi lebih baik. Suchyadi mengungkapkan bahwa perbedaan karakter anak dengan kebutuhan yang beragam akan membutuhkan kemampuan guru untuk menggabungkan berbagai kemampuan dan bakat masingmasing anak [8]. Praktik supervisi adalah pengembangan teori yang berguna untuk memberi perhatian pada aspekaspek kepemimpinan instrumental dalam instruksional, bersifat lebih taktis dan pengacu kepada pengembangan alat kebutuhan untuk mencapai tujuan tertentu bagi supervisor.

Menurut Burton [9], Supervisi ditujukan pada perbaikan dan peningkatan kualitas pengajaran, membina program pengajaran yang ada sebaik-baiknya, sehingga selalu ada usaha memperbaiki faktor-faktor yang mempengaruhi proses pembelajaran peserta didik. Fungsi utama supervisi bukan perbaikan dan pembelajaran saja, 
tetapi untuk mengkoordinasi, menstimulasi, dan mendorong ke arah pertumbuhan profesi guru.

Memperbaiki situasi belajar mengajar dapat dilakukan dengan cara supervisi oleh kepala sekolah. Kepala sekolah melaksanakan tugasnya sebagai supervisor, diharapkan dapat bertindak sebagai konsultan yang dinamis dan mampu menyiapkan kegiatan-kegiatan, baik yang bukan bentuk fisik maupun psikis, seperti pendidikan, pelatihan, instruksi, penyuluhan, saran, dorongan yang dapat menolong bawahan, dalam meningkatkan kemampuan melaksanakan tugas dan menyesuaikan diri dengan perkembangan yang terjadi.

Menurut Daryanto [10] Secara umum kegiatan supervisi mengikuti karakteristik, yaitu memberikan bantuan kepada anggota organisasi sekolah untuk mengembangkan proses/kegiatan yang lebih baik dalam upaya meningkatkan mutu pendidikan. Supervisi pendidikan dapat mengembangkan proses pendidikan yang lebih baik, karakteristik supervisi ini meliputi:

1. Supervisi memperlakukan manusia sebagai manusia seutuhnya baik sebagai manusia perorangan, sosial ataupun mahkluk ciptaan Tuhan,

2. Supervisi diarahkan untuk meningkatkan mutu kegiatan organisasi sekolah,

3. Pelaksanaan supervisi hendaknya dilaksanakan secara musyawarah, saling menghormati, bersedia menerima pendapat orang lain dan menyatakan pendapatnya sendiri.

4. Supervisi hendaknya memperhatikan kesejahteraan personel yang meliputi kebutuhan perseorangan dan sosialnya,

5. Supervisi hendaknya dilaksanakan oleh orang yang telah mendapat pendidikan atau latihan dalam bidang supervisi.

Karakteristik supervisi tersebut menggambarkan kegiatan yang berorientasi pada kemanusiaan dan kesadaran dalam menjalankan tugas kerja yang dibebankan tanpa ada rasa paksaan yang bersifat membelenggu, tetapi mengarahkan supervisi untuk mencapai tujuan pendidikan yang telah ditentukan bersama.

Pada prinsipnya kegiatan supervisi selalu diperlulan pada setiap organisasi, kegiatan tersebut bertujuan untuk menciptakan kondisi kerja dan mengembangkan perilaku anggota organisasi yang diperlukan bagi pencapaian tujuan organisasi tersebut secara efektif.

Berdasarkan kajian teori di atas dapat disimpulkan bahwa Supervisi kepala sekolah adalah suatu usaha yang dilakukan kepala sekolah dalam membina, mendorong dan mengarahkan guru agar dapat mencapai tujuan pendidikan secara efektif . Adapun indikatornya adalah: 1) pengawasan dalam pendidikan, 2) pembinaan kepada guru, 3) pembinaan tanggung jawab guru 4) pengevaluasian pelaksanaan KBM.

\section{METODE PENELITIAN}

Secara umum penelitian ini bertujuan untuk meneliti supervisi kepala sekolah dan variabel-variabel yang memiliki hubungan dengan supervisi kepala sekolah, dalam hal ini adalah kecerdasan emosional, dan kepuasan kerja guru.
Secara khusus penelitian ini bertujuan untuk mengetahui hubungan antara supervisi kepala sekolah dengan kepuasan kerja

Metode yang digunakan dalam penelitian ini adalah metode survei dengan pendekatan korelasional. Variabel penelitian terdiri dari dua variabel bebas yaitu supervisi kepala sekolah (X) dengan variabel terikat yaitu kepuasan kerja guru $(\mathrm{Y})$.

Untuk mendapatkan data di lapangan digunakan kuesioner yang disusun berdasarkan indikator-indikator yang ada dalam variabel penelitian. Data primer yang dibutuhkan adalah data mengenai supervisi kepala sekolah dengan variabel terikat yaitu kepuasan kerja guru SD Negeri Di Kecamatan Bogor Utara.

\section{HASIL DAN PEMBAHASAN}

Berdasarkan hasil pengujian hipotesis, terbukti ketiga hipotesis yang diajukan dapat diterima secara signifikan. Secara keseluruhan penelitian ini menunjukkan terdapat hubungan positif antara: 1) hubungan antara Supervisi Kepala Sekolah dengan Kepuasan Kerja, 2) hubungan antara Kecerdasan Emosional dengan Kepuasan Kerja, 3) hubungan antara Supervisi Kepala Sekolah dan Kecerdasan Emosional secara bersama-sama dengan Kepuasan Kerja. Hubungan fungsional yang terbentuk antara variabel bebas dan variabel terikat menunjukkan bahwa Kepuasan Kerja merupakan hasil variabel Supervisi Kepala Sekolah dan Kecerdasan Emosional. Uraian ketiga hipotesis itu dijelaskan sebagai berikut.

Hasil penelitian menunjukkan bahwa terdapat hubungan positif antara Supervisi Kepala Sekolah dengan Kepuasan Kerja. Hal ini ditunjukkan oleh koefisien korelasi $\left(r_{y}\right)$ sebesar 0,52 yang dinyatakan sangat signifikan. Kontribusi Supervisi Kepala Sekolah terhadap Kepuasan Kerja sebesar 26,6\% yang dinyatakan dengan nilai koefisien determinasi $\left(r_{y}\right)$ sebesar 0,266. Koefisien korelasi parsial Supervisi Kepala Sekolah (dengan variabel lain dikendalikan) adalah sebesar 0,47 yang dinyatakan sangat signifikan.

Berdasarkan persamaan regresi linier sederhana $\hat{Y}=$ $63,64+0,53 \mathrm{X}$, diprediksi bahwa setiap kenaikan satu skor Supervisi Kepala Sekolah akan menyebabkan kenaikan 0,53 skor Kepuasan Kerja pada konstanta 63,64. Hasil penelitian ini menyimpulkan bahwa Supervisi Kepala Sekolah yang dimiliki memberikan kontribusi positif yang berpengaruh nyata terhadap Kepuasan Kerja.

Hal ini sesuai dengan teori yang dikemukakan oleh Burton [9], Supervisi kepala sekolah merupakan perbaikan dan peningkatan kualitas pengajaran, membina program pengajaran yang ada sebaik-baiknya, sehingga selalu ada usaha memperbaiki faktor-faktor yang mempengaruhi proses pembelajaran peserta didik. Fungsi utama supervisi bukan perbaikan dan pembelajaran saja, tetapi untuk mengkoordinasi, menstimulasi, dan mendorong ke arah pertumbuhan profesi guru.

Hal ini berarti semakin tinggi Supervisi Kepala Sekolah maka makin tinggi pula hasil Kepuasan Kerja guru, begitu pula sebaliknya, semakin rendah Supervisi Kepala 
Sekolah maka makin rendah pula hasil Kepuasan Kerja guru. Dengan demikian temuan fakta dan data dalam analisis penelitian ini semakin mendukung temuan-temuan terdahulu mengenai adanya hubungan positif antara Kepuasan Kerja guru dengan Supervisi Kepala Sekolah.

Dengan demikian temuan fakta dan data dalam analisis penelitian ini semakin mendukung temuan-temuan terdahulu mengenai adanya hubungan yang kuat antara Supervisi Kepala Sekolah terhadap Kepuasan Kerja baik secara langsung ataupun tidak langsung.

Berdasarkan hasil penelitian dan pembahasan di atas, maka dapat diindikasikan bahwa salah satu upaya untuk meningkatkan Kepuasan Kerja adalah dengan meningkatkan atau mengembangkan Supervisi Kepala Sekolah nya.

\section{SIMPULAN}

Dari Hasil pengujian terhadap hipotesis pertama, menggambarkan bahwa terdapat hubungan positif dan sangat signifikan antara Supervisi Kepala Sekolah (X) dengan Kepuasan Kerja Guru (Y). Persamaan regresi antara kedua variabel tersebut adalah $\hat{\mathrm{Y}}=63,64+0,53 \mathrm{X}$, yang berarti setiap penambahan satu unit variabel Supervisi Kepala Sekolah akan menyebabkan kenaikan variabel Kepuasan Kerja Guru sebesar 0,53 pada konstanta 63,64. Tingkat keeratan hubungan menghasilkan koefisien korelasi $\left(\mathrm{r}_{\mathrm{y}}\right)$ sebesar 0,52. Besarnya kontribusi variabel Supervisi Kepala Sekolah dalam menerangkan Kepuasan Kerja Guru ditunjukkan dengan koefisien determinasi $\mathrm{r}^{2}{ }_{\mathrm{y}}=0,226$ atau $22,6 \%$ selebihnya $77,4 \%$ Kepuasan kerja guru dipengaruhi oleh faktor lain.

\section{REFERENSI}

[1] Y. Suchyadi and Nurjanah. 2018, Relationship between Principal Supervision in Increasing the Job Satisfaction of Private Junior High School Teachers in East Bogor District," J. Humanit. Soc. Stud., vol. 02, no. 01, pp. 26-29.

[2] Y. Suchyadi, 2017. "Relationship between Work Motivation and Organizational Culture in Enhancing Professional Attitudes of Pakuan University Lecturers," vol. 01, no. 01.

[3] J. Wood, J. Wallace and R.M. Zeffane, 2001. Organisational Behavior: A Global Perspective, 2nd Edittion (Milton, Qld: John Wiley \& Sons Austalia, Ltd.

[4] Luthans, Fred. 2006, Prilaku Organisasi edisi 10,Yogyakarta: ANDI Yogyakarta.

[5] Kreitner, Robert and Angelo Kinicki. 2009. Organizational Behavior. New York: McGraw-Hill.

[6] Handoko, T. Hani. 2001. Manajemen Personalia dan Sumber Daya Manusia. Yogjakarta: BPFE.

[7] Syariful Sagala, 2006. Administrasi Pendidikan Kontemporer, Bandung: Alfabeta,.

[8] Y. Suchyadi, Y. Ambarsari, and E. Sukmanasa,. 2018.
Analysis of Social Interaction of Mentally Retarded Children," J. Humanit. Soc. Stud., vol. 02, no. 02, pp. 17-21.

[9] Burton \& Bruckner. 2000. Supervision. New York: Appleton Century. Craff, Inc,2000

[10] Daryanto. 2001. Administrasi Pendidikan. Jakarta: Rineka Cipta. 2001. 